\title{
HIV AND INFANT FEEDING - ONE STEP FORWARD, TWO STEPS BACK
}

\author{
H Saloojee ${ }^{\mathbf{1}}, M B B C h$, FCPaed (SA), MSc \\ G Gray $^{2}, M B B C h$, FCPaed (SA) \\ J A McIntyre ${ }^{3,4}, M B B C h, F R C O G$ \\ ${ }^{I}$ Division of Community Paediatrics, University of the Witwatersrand, Johannesburg \\ ${ }^{2}$ Perinatal HIV Research Unit, University of the Witwatersrand \\ ${ }^{3}$ Anova Health Institute, Johannesburg \\ ${ }^{4}$ Centre for Infectious Diseases Epidemiology and Research, School of Public Health and Family Medicine, University of Cape Town
}

The recent decision by the South African Department of Health to withdraw the provision of free replacement (formula) feeds to HIV-exposed infants has hardly evoked any response from clinicians, health professionals or civil society groups. This paper argues that the decision is short-sighted, lacks an adequate evidence base, and is retrogressive and unconstitutional. Nine supporting arguments are presented and an alternative policy proposed.

The recent 'Tshwane Declaration of Support for Breastfeeding in South Africa' championed by the national Department of Health seeks to promote breastfeeding and halt practices deterring optimal breastfeeding in South Africa (SA). ${ }^{1}$ The Declaration's intentions are most welcome, including greater support for the Baby Friendly Hospital Initiative which facilitates breastfeeding soon after birth, increasing numbers of community health promoters who will visit homes and support mothers with breastfeeding, workplace support for breastfeeding mothers, and stricter monitoring of the milk industry's compliance with the code of marketing of breastmilk substitutes.

However, one decision stands out as short-sighted, poorly evidenced and retrogressive. The plan to remove the provision of free replacement (formula) feeding to infants of HIV-positive women is frankly bewildering. HIV accounts for over $50 \%$ of child mortality in $S A,{ }^{2}$ and is primarily responsible for the loss of hard-earned gains in child health in South Africa over the past two decades. Postnatal transmission of HIV through breastfeeding is now the commonest form of mother-to-child transmission (MTCT), and its contribution is increasing as programmes introduce more effective antenatal and perinatal ARV regimens. Annually, more than half a million infants globally acquire HIV through breastfeeding, highlighting the failure of previous strategies, including those promoting exclusive breastfeeding.

There are currently only two recognised postnatal preventive strategies - antiretroviral prophylaxis provided to mother or infant, and avoiding HIV exposure through replacement feeding. To deliberately discard one of these two strategies is a luxury that the country can ill afford and requires substantial evidence that the strategy is either ineffective or results in major harm. Evidence to support either of these contentions in the South African setting is simply lacking.

\section{REPLACEMENT (FORMULA) FEEDING REMAINS}

A LEGITIMATE HIV PREVENTION STRATEGY

Multiple strategies are currently available to prevent HIV transmission in adults. Despite good evidence about the benefit of condoms, microbicides, circumcision and pre- and post-exposure prophylaxis, among others, the search continues for different and more effective prevention options such as an HIV vaccine. Clearly, a single strategy could never meet the needs of all. If the Department of Health were to summarily withdraw the provision of any one of the established HIV prevention strategies, the HIV community would be toyi-toying in the streets.

Yet the government's decision to remove a wellevidenced child HIV prevention strategy - replacement feeding - has hardly elicited a whisper from HIV activists, clinicians or civil society. Is it that they have been cowed into inaction because supporting replacement feeding is somehow automatically viewed as being anti-breast? Certainly, this was the fate of the authors of this piece when we recently wrote an opinion piece in the Mail \& Guardian questioning the validity of the Department's decision. ${ }^{3}$ Supporters of the Department's proposal lambasted the newspaper's irresponsible behaviour in publishing the piece. They went on to describe us as illinformed and 'dissidents'. ${ }^{4}$ Such malicious name-calling demonstrates a degree of intolerance unbecoming of fellow scientists on a decision that has great scientific and public health importance and deserves rigorous debate.

Indeed, at an open public debate hosted by the SA HIV Clinicians Society in Johannesburg in October 2011, over $70 \%$ of the more than 120 attendees (who included doctors, nurses, policy makers and nutritionists) voted against the Department's proposed change. A similar percentage of attendees agreed that provinces should be free to determine their own policy rather than being 
forced to offer a single option. Clearly the views of many important stakeholders have not been considered in the Department's decision, and there appear to be many dissidents lurking out there. The most silent voice has been that of HIV-positive women.

\section{NO EVIDENCE THAT THE NEW PROPOSAL WILL} MAXIMISE HIV-FREE CHILD SURVIVAL IN SA Supporters of the withdrawal of replacement feeding will quickly point out that it is not just the acquisition of HIV infection but overall child survival (HIV-exposed children staying alive) that matters. That is correct. The pertinent question then is whether replacement feeding inevitably results in increased child mortality in SA. The primary author of the Mail \& Guardian piece attacking our stance readily acknowledged in a paper published in the Bulletin of the World Health Organization in 2011 that '... no determination has been made about which feeding practice will maximize HIV-free survival nationally'. ${ }^{5}$

Much of the evidence arguing that HIV-free survival (being alive and HIV uninfected) is similar for formulafed and exclusively breastfed infants originates from countries such as Zambia, Malawi and rural Botswana. However, the extremely high background mortality in the study children (e.g. $21 \%$ in Zambia) ${ }^{6}$ because of the high burden of infectious disease, poor hygiene and sanitation, and limited access to quality health care, easily masks any possible benefits of replacement feeding (since so many children die). These dismal conditions are much less likely in South African settings. In rural KwaZuluNatal, for instance, the probability of HIV-free survival at 18 months was marginally higher in HIV-exposed infants who had never been breastfed compared with infants who had ever been exclusively breastfed $(80 \% \mathrm{v}$. $75 \%, p=0.05$ ), the difference being mostly attributed to acquisition of infection through breastfeeding. ${ }^{7} A$ second confounder present in most studies is that since few trials randomised feeding choice, higher-risk women (with lower CD4 counts) were directed to, or selected, replacement feeding. This obviously attenuates possible benefits of replacement feeding.

Evidence from diverse African cities such as Nairobi ${ }^{8}$ and $\mathrm{Abidjan}^{9}$ convincingly indicates that replacement feeding can be safely supported in these settings and can reduce HIV infection rates, without jeopardising child survival. With safe replacement feeding, the vertical HIV transmission rate can be reduced to less than $2 \%$, even in a resource-limited setting such as rural Rwanda. ${ }^{10}$ The high HIV-free survival rate reported in the Rwandan cohort of infants whose caregivers were supported with exclusive replacement feeding is remarkable and among the highest reported for a cohort of HIV-exposed infants. ${ }^{10}$

\section{SOUTH AFRICA IS NOT A SINGLE HOMOGENEOUS COUNTRY}

Using data from poorer southern African countries to argue that replacement (formula) feeding cannot be undertaken safely in SA is inappropriate. Over half of South African children are urbanised. ${ }^{11}$ Many have good access to safe water (62\%), sanitation (63\%) and electricity, and these statistics exceed $87 \%$ in Gauteng and the Western Cape, including their townships and informal settlements. ${ }^{12}$ Under-5 mortality rates (U5MR) vary substantially among provinces and districts; for example, in 2008 the U5MR in Western Cape was $31 / 1000$ live births, while it was almost fourfold higher in the Free State $(117 / 1000) \cdot{ }^{13}$ District-level data are unavailable.

At least a third to one-half of SA caregivers should therefore be able to safely replacement feed their children. SA data from peri-urban and rural settings such as Paarl, Umlazi and Rietvlei confirm that formula feeding halved HIV transmission or death among children living in households with piped water. Among those who had piped water and fuel and who disclosed their HIV status, the protective effect of formula was greater $(68 \%$ reduction). ${ }^{14}$ Furthermore, the increasing availability of rotavirus and pneumococcal vaccine in SA is rapidly reducing the incidence and severity of diarrhoea and pneumonia, two major morbidities associated with replacement feeding.

This does not mean that that choosing to formula feed an infant in some rural parts of the country, or in an underserviced informal settlement, could ever be considered an appropriate choice. However, denying individual choice and failing to support a legitimate HIV prevention strategy in circumstances where this can be safely done violates caregivers' and infants' rights to basic health care and may be unconstitutional.

\section{A SINGLE INFANT FEEDING OPTION IS INAPPROPRIATE FOR ALL HIV-POSITIVE WOMEN IN SA}

A 'one-size-fits-all policy' is certainly simpler to promote, and the notion that 'mixed messages lead to mixed feeding' makes sense. However, the simplest policy is not necessarily the best. Until recently infant feeding policy in SA was made at the provincial level. This makes sense because $S A$ is heterogeneous in so many respects - the rural-urban mix, the availability of water and sanitation, the background infant mortality and the provincial variation in the percentage of mothers with HIV. The newly proposed policy demands that the whole country assume the same position - no free formula provision. This position is contrary even to the 2010 WHO HIV and infant feeding policy, on which the South African policy is based, which recommended that decisions be made by 'national or sub-national health authorities' in recognition of in-country variances. ${ }^{15}$

\section{THE NEW PROPOSAL IS RETROGRESSIVE IN TERMS OF SUPPORTING WOMEN'S CHOICE AND ANTI-POOR}

Arguing that parents can pay for formula from their own pockets if they choose this option may seem reasonable, but this denies access to an estimated 25000 infants in whom formula feeding may be safely undertaken, but is unaffordable. Data from Rietvlei, Paarl and Umlazi confirmed that as many as a third of women living in these peri-urban and rural settings met the adequacy for replacement feeding criteria, dubbed AFASS 
(affordable, feasible, acceptable, sustainable, safe), despite being poor. ${ }^{14}$ Disallowing middle- and upperclass women access to free state-sponsored formula may be justifiable, since access to many health services for this class of citizens require them to bear the costs themselves. However, insisting that a poor woman (who qualifies for a child support grant, for instance) who meets the AFASS criteria be denied the opportunity to have an HIV-uninfected child, simply because she is poor, is discriminatory.

\section{THE NEW PROPOSAL IS BASED ON} EXTRAPOLATION RATHER THAN FIRM EVIDENCE Much of the enthusiasm for the proposal to withdraw support for replacement feeding stems from research suggesting that extended nevirapine provision to infants for 6 months, or triple antiretroviral therapy provision to their mothers, can reduce HIV transmission rates to less than $2 \%$ at 6 months in exclusively breastfed populations. Whether the benefits of antiretroviral prophylaxis continue to 12 months (the suggested duration in SA), and whether the intervention is equally beneficial in mixed-fed infants (the likely situation in SA), is unknown. Similarly, the consequences of antiretroviral interruption while breastfeeding are unclear. There are further unanswered questions. How serious are the long-term effects of exposure to multiple antiretroviral drugs in utero and during breastfeeding? Can adequate adherence be achieved to avoid emergence of drug resistance? Will there be negative effects on discontinuation of antiretroviral therapy (ART) after stopping breastfeeding in women who do not require it for their own health?

\section{THE ABILITY OF THE HEALTH SYSTEM TO SUPPORT THE NEW PROPOSAL IS NOT GUARANTEED - FAILURE TO DELIVER WILL HAVE DRASTIC CONSEQUENCES}

The new proposal is a huge public health experiment and could even be considered a high-stake gamble. While nevirapine toxicity does not seem cumulative, the adherence and programmatic challenges of long-term prophylaxis are untested. Extrapolating data from highly controlled experimental settings to real-world situations is risky, particularly in the absence of a single local pilot project demonstrating successful implementation. At present, not one province has any monitoring or evaluation plan to establish effectiveness.

Perhaps the most pertinent question is whether many South African settings that are still battling to provide single-dose nevirapine or dual therapy are capable of offering this new standard of care. What should not be under-estimated are the demands on the health system of the new proposal. It is anticipated that of the approximately 300000 HIV-positive pregnant women each year, about half will qualify for ART (for life) for their own health. For these mothers ensuring adherence is the major issue, since their infants will not be receiving nevirapine, and if the mother stops taking ART her infant will be left with no prophylaxis. Mothers not qualifying for ART need to be convinced to exclusively breastfeed for 6 months, and to provide their healthy uninfected infants with a daily dose of a drug (nevirapine) for up to one year. The health service will need to monitor these children at least monthly and ensure that drug supplies do not falter. The benefit of extended nevirapine if a mother starts mixed feeding or forgets to provide the drug for any period is unknown.

A failure to meet any of these requirements will mean that transmission rates of infant HIV could start escalating again. All the problems of ensuring an adequate formula supply that have plagued the PMTCT programme will be replicated with extended nevirapine or ART provision, except that the consequences of a failed supply line will be far worse; while mothers still had to feed their infants and make alternative plans when formula was scarce, it is less likely that they will do so when nevirapine or ARTs runs out at a clinic.

Little consideration seems to have been taken in the new proposal of the myriad of situations where initiation or continuation of breastfeeding of HIV-exposed infants will not be possible, such as mothers returning to work or school, grannies caring for grandchildren, and abandoned or orphaned children.

\section{SOUTH AFRICAN DATA INDICATE REPLACEMENT FEEDING AS AN HIV-PREVENTION STRATEGY IS COST EFFECTIVE DEPENDING ON MORTALITY RATES}

During this time of fiscal restraint where healthcare resources are finite, information about both effectiveness and costs is important for policy makers as evidencebased decisions are made. When the issue of costs was raised during the recent breastfeeding consultation, the comment that 'a back of the envelope calculation shows that breastfeeding is much cheaper and more cost-effective than formula and could save R200 million a year' was met with wild applause. This type of feeble evidence to support a major policy shift is unfortunate. Cost, logistics and cultural preferences should be considered in policy decisions.

A new, unpublished modelling exercise using SA data indicates that extended nevirapine is a cost-saving intervention in both typical urban and rural settings and results in improved HIV-free survival. Changing feeding practices to promote breastfeeding is cost-saving in typical rural settings, while promoting replacement feeding in typical urban settings is the most costeffective feeding option (personal communication, Mandy Maredza, 1 November 2011).

\section{AN HIV-FREE GENERATION CAN NEVER BE} ACHIEVED WHILE BREASTFEEDING CONTINUES The current call and challenge posed by the UNAIDS, and taken up in SA national policy, to eliminate MTCT by 2015 (i.e. zero new HIV infections) is unlikely to be achieved with a single strategy for infant feeding in SA, since at least 6000 new infections annually can be expected in breastfeeding infants provided extended nevirapine. In reality there will be many more infected children, since implementation will hardly be perfect 
because of imperfect behavioural compliance. In the rush to ensure that SA is on a path to decreasing child mortality from all causes it is critical to ensure that recent gains in the number of HIV-exposed children's lives saved through existing interventions, including replacement feeding, are not erased.

\section{WHAT A NEW POLICY SHOULD SAY}

A more appropriate infant feeding policy for the country would offer antiretroviral prophylaxis and breastfeeding as the national default option. However, provinces, and perhaps even districts, should be allowed the freedom to decide whether they wish to continue to support the provision of replacement feeding for poor women who meet the AFASS criteria, based on their own circumstances. Whatever choice women ultimately make, much more emphasis needs to be placed on a more supportive environment including adequate counselling, education and support through community health workers.

The availability of antiretroviral prophylaxis is a big step forward for HIV-positive women choosing to breastfeed their infants. It's a crying shame that in introducing this promising intervention, the Department of Health has chosen to take the low road (by insisting on a single option) rather than following the high one where the provision of safe water, sanitation and other resources, and employment would also have been prioritised for all citizens, so that any parents wanting to guarantee a HIVfree future for their child could do so knowing that the choice of replacement feeding could be safely supported too.

\section{REFERENCES}

1. The Tshwane Declaration of breastfeeding in South Africa. http://www.confcall.co.za/ presentationDownloads. php?recordld $=8$ (accessed 13 November 2011).

2. Stephen CR, Bamford LJ, Patrick ME, Wittenberg DF, eds. Saving Children 2009 Five Years of Data. A Sixth Survey of Child Healthcare in South Africa. Pretoria: Tshepesa Press, MRC, CDC, 2011.

3. Saloojee H, Gary G, McIntyre J, Violari A. Breast may be best, but tread cautiously. Mail and Guardian 9 September 2011. http://mg co.za/article/2011-09-09-breastmay-be-best-but-tread-cautiously (accessed 13 November 2011).

4. Doherty D, Sanders D, Goga A, et al. Stop dithering at death's door. Mail and Guardian, 16 September 2011. http://mg.co.za/article/2011-09-16-stop-dithering-atdeaths-door/ (accessed 13 November 2011)

5. Doherty T, Sanders D, Goga A, et al. Implications of the new WHO guidelines on HIV and infant feeding for child survival in South Africa. Bull World Health Organ 2011;89:62-67.

6. Kuhn L, Aldrvandi GM, Sinkala M, et al. Effects of early, abrupt weaning on HIV-free survival of children in Zambia. N Engl J Med 2008:359:130-141.

7. Rollins NC, Becquet R, Bland RM, et al. Infant feeding, HIV transmission and mortality at 18 months: the need for appropriate choices by mothers and prioritization within programmes. AIDS 2008;22:2349-2357.

8. Nduati R, John G, Mbori-Ngacha D, et al. Effect of breastfeeding and formula feeding on transmission of HIV-1: a randomized clinical trial. JAMA 2000:283:1167-1174.

9. Leroy V, Ekouevi DK, Becquet R, et al. 18-month effectiveness of short-course antiretroviral regimens combined with alternatives to breastfeeding to prevent HIV mother-to-child transmission. PLoS One 2008;3:e1645.

10. Franke MF, Stulac SN, Rugira IH, et al. High human immunodeficiency virus-free survival of infants born to human immunodeficiency virus-positive mothers in an integrated program to decrease child mortality in rural Rwanda. Pediatr Infect Dis J 2011;30:614-616.

11. Hall K. Children's access to housing. In: Jamieson L, Bray R, Viviers A, Lake L, Pendlebury S, Smith C, eds. South African Child Gauge 2010/2011. Cape Town: Children's Institute, University of Cape Town, 2011.

12. Hall K. Children's access to basic services. In: Jamieson L, Bray R, Viviers A, Lake L, Pendlebury S, Smith C, eds. South African Child Gauge 2010/2011. Cape Town: Children's Institute, University of Cape Town, 2011.

13. Statistics South Africa. Mortality and causes of death in South Africa, 2008: Findings from death notification. Statistical release P0309.3, 2010.

14. Doherty T, Chopra M, Jackson D, et al. Effectiveness of the WHO/UNICEF guidelines on infant feeding for HIV-positive women: results from a prospective cohort study in South Africa. AIDS 2007:21:1791-1797.

15. World Health Organization. Guidelines on HIV and Infant Feeding 2010. Principles and Recommendations for Infant Feeding in the Context of HIV and a Summary of Evidence. Geneva: WHO, 2010. 